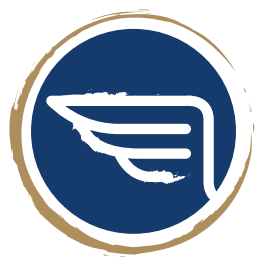

\title{
Madre y destino en la tragedia griega.
}

Una reflexión sobre la heroicidad.

\section{Ethel Beatriz Junco}

Instituto de Humanidades

Universidad Panamericana, campus Aguascalientes

ejunco@up.edu.mx

\section{Olivia Cáttedra}

CONICET, Argentina

ocattedra@gmail.com 


\section{Madre y destino en la tragedia griega.}

Una reflexión sobre la heroicidad
Autoras: Ethel Beatriz Junco

Profesora investigadora del Instituto de Humanidades, Universidad Panamericana, campus Aguascalientes.

Olivia Cáttedra

Investigadora de CONICET, Argentina.

Es necio el mortal que destruye ciudades, si además deja en soledad templos y tumbas -santuarios de los muertos- prepara su propia destrucción para después.

Eur. Tro. 95-7

A partir de dos tragedias de Eurípides, revisamos la figura de madre mítica en función de paradigma cultural en orden a establecer relaciones históricas. Vinculamos la perspectiva del helenismo del siglo IV y los fenómenos contemporáneos sobre tres claves: el distanciamiento de lo divino y su intento de resignificación a través de una ética horizontal, la generalización de la violencia como estadio de convivencia normalizado, la necesidad de referentes a nivel individual y social. En los textos elegidos, el motivo del destino enfocado desde las consecuencias de la guerra desarrolla tipos contrastantes de heroicidad; entre ellos, Hécuba, la reina madre convertida en viuda y testigo del fin de su descendencia, hace la propuesta distintiva, por medio de la renovación de la idea de justicia y de la revalorización del sufrimiento con sentido trascendente. Eurípides ofrece una alternativa, que cuestiona la idea de civilización ante la crisis de su mundo tradicional -abandono de los dioses, arbitrariedad de los hombres, sojuzgamiento de los inocentes. Si la tragedia propone una actualización del mito de Troya en sede clásica -Atenas de la democracia- su relectura ofrece herramientas de análisis para una contemporaneidad debilitada en su fe trascendente y vulnerada en sus relaciones interpersonales.

Palabras clave: tragedia, Eurípides, helenismo, Hécuba, heroicidad.
Based on two tragedies by Euripides, we review the mythical mother figure as a cultural paradigm in order to establish historical relationships. We link the perspective of 4th century Hellenism and contemporary phenomena on three keys: the distancing from the divine and its attempt of resignification through a horizontal ethics, the generalization of violence as a normalized stage of coexistence, the need of referents at individual and social level. In the chosen texts, the motif of destiny focused from the consequences of war develops contrasting types of heroism; among them, Hecuba, the queen mother turned widow and witness of the end of her offspring, makes the distinctive proposal, through the renewal of the idea of justice and the revaluation of suffering with a transcendent sense. Euripides offers an alternative, which questions the idea of civilization in the face of the crisis of its traditional world-abandonment of the gods, arbitrariness of men, subjugation of the innocent. If the tragedy proposes an update of the myth of Troy in a classical setting -Athens of democracy-its re-reading offers analytical tools for a contemporaneity weakened in its transcendent faith and violated in its interpersonal relationships.

Keywords: tragedy, Euripides, Hellenism, Hecuba, heroism. 


\section{Planteamiento del problema}

La elección de un modelo de madre en sede mítica -atendiendo a la virtualidad de todo mitologema- permite establecer un nexo hacia situaciones y necesidades que involucran el campo de las relaciones interpersonales y sus fundamentos en escenario histórico actual.

Nos interesa destacar asociaciones en tres niveles especialmente:

1. Cosmovisiones afectadas por la percepción del distanciamiento de lo divino, en tanto guía providencial de los acontecimientos.

2. Generalización de la violencia interpersonal, independiente de la defensa de la justicia.

3. Búsqueda de sentido horizontal, sin auxilio de la trascendencia.

Las obras clásicas elegidas para el análisis y nuestra época presente comparten esta descripción de realidad.

Sobre las anteriores condiciones de fragilidad, descriptas en buena parte de los textos supervivientes de Eurípides, pero destacadas en los elegidos para nuestro comentario, consideraremos la advertencia acerca del destino y de la guerra, corporizada en la conducta del héroe y su empleo de la justicia. Éste es el campo de los cuestionamientos euripídeos; dentro de él se yergue la figura materna que, sin poner las condiciones, las padece.

El reclamo de un nuevo orden parte de su diferenciación. La figura civilizada de la madre configurará dos perfiles complementarios e igualmente proactivos, ocupándose de:

1. La recomposición de la justicia, produciendo su reorientación.

2. La re-creación de la vida, a partir de la re-significación del sufrimiento y en consecuencia, la propuesta de fundamentos para un vínculo social vulnerado.

A las circunstancias de inseguridad que definen el mundo euripídeo, y que condicionan el futuro, la madre opondrá una alternativa de consistencia. Si el punto de partida es la fragilidad, el punto de llegada es el modo de enfrentamientoํ. De aquí que utilicemos la interrelación destino-madre: si el destino es lo no-intercambiable, el carácter materno

1. Luigi Pati, "La famiglia, sistema relazionale fragile e vulnerabile, ma ricco di risorse". En La Famiglia, Rivista di problemi familiari, (Brescia:Editrice La Scuola, 2015), 11. 
es capaz de mejorarlo. A la fragilidad de la vida, la consistencia de la virtud.

\section{Sobre la madre en la tragedia}

La figura de la mujer encuentra en la tragedia un espacio de privilegio. El desarrollo del género trágico, contemporáneo al ascenso y descenso de la democracia que formula Atenas en particular, ofrece campo de expansión para el análisis del papel femenino, de las prácticas que lo definen y de la realización dentro de su propia naturaleza, atribuciones implícitas en un contexto de imperativos masculinos.

La definición del protagonismo del hombre en el devenir histórico expone los alcances de lo femenino. Así como el varón, en el horizonte épico-aristocrático, es el héroe de la guerra mediante el combate, y el político lo es de la ciudad en territorio de la democracia, la mujer es dadora de hombres para la guerra o para la política, garantizando la continuidad del estado ${ }^{2}$. Ser madre en Grecia es un privilegio, en tanto inserta en el espacio cultural establecido: hace a la esposa en el matrimonio partícipe de la vida política, al proveer hijos al varón y a la ciudad; por la procreación es capaz de participar de la familia del esposo $^{3}$. En los importantes estudios que describen las posibles funciones de la mujer en la sociedad, es recurrente la coincidencia en que el papel de la maternidad representa la culminación de su naturaleza ${ }^{4}$.

En la tragedia, como cohesión de tradición mítico-religiosa e imperativo histórico, se ponen en acción más modelos de lo femenino de los que la sociedad visibiliza. Eurípides destaca por aportar tales facetas en complejidad superior a cualquier otro autor ${ }^{5}$. Dentro de su producción, nos detendremos en la figura de Hécuba, leída en dos obras, la misma Hécuba y Las Troyanas, por aglutinar simbólicamente en su persona todo el mal de la guerra y por la simetría que alcanza el personaje materno respecto de sí mismo ${ }^{6}$.

2.S. Campese, P. Manuli y G. Sissa, Madre materia. Sociología e biología della donna greca(Torino: Boringhieri Editori, 1983), 16.

E. Cantarella, La calamidad ambigua. Condición e imagen de la mujer en la antigüedad griega y romana, (Madrid: Ediciones Clásicas, 1991[1985]), 91 ss.

3. Cantarella, E, Op, Cit., 75.

4. N. Loraux, Las experiencias de Tiresias. Lo masculino y lo femenino en el mundo griego

(Barcelona: EditorialAcantilado, 2004[1990]), 405.

5. JC. Kamerbeek, "Mythe et Réalité dans l'OEuvre d'Euripide”, Entretiens sur l'Antiquité Classique.

(Ginebra: Fondation Hardt VI, 1960), 25.

6. G.M.A Grube, The Drama of Euripides (Londres: Methuen, 1941), 272; D.J. Conacher, Euripidean Drama. Myth, Theme and Structure (Toronto: University of Toronto Press, 1967), 138. 
En el cierre de la Ilíada, Hécuba es presentada como madre sufriente cuando lamenta la pérdida de Héctor ${ }^{7}$. El llanto que enmarca el final de la obra oficia de prefiguración: el fin mítico de Troya es el inicio de la historia griega. La madre la concluye y la inicia en llanto. La reina de Troya es observada por Eurípides en su triple condición de desgraciada, luego de haber perdido hijos, marido y trono ${ }^{8}$; de esta lectura interesa el modo de operar de la madre después de que ha perdido su areté . Hécuba, figura de la maternidad por antonomasia, dadora de héroes al esposo, rey de la ciudad ilustre, ha pasado del apogeo a la derrota y debe redefinir su carácter. Allí se sustentará un modo renovado de destino para los suyos, que transitará el complejo proceso del reclamo y la condena, al del asentimiento y la compasión.

Cuando Hécuba pierde todos sus hijos, se quebranta su condición femenina; haber perdido marido e hijos la excluye de la protección del orden masculino y corre el riesgo de desaparecer como mujer. Pasa de ser libre a cautiva ${ }^{10}$. Esa valoración, propia del entorno cultural, la expone a mimetizarse o resistir; al decidir defenderse, se asigna nuevos rasgos, rompe los patrones tradicionales y excede lo esperable. De ese modo, se entabla su lucha contra el destino: para oponerse a las desgracias inmerecidas de sus descendientes, deberá ser al menos tan osada como las fuerzas que actúan por encima del hombre.

La mitología abunda en actos infaustos de oposición al destino; no se trata aquí de ello. Hécuba no puede cambiar la Moira de sus hijos, reservados a ser grandes, pero a caer en la batalla o en sacrificios consecuentes; pero sí puede interferir en su hypermóron, en aquellas acciones que quedan por encima de la determinación inicial del destino.

\section{La madre como destino}

Con Homero queda abierto un problema central del pensamiento religioso y filosófico, la noción de destino. ${ }^{11}$ La Moira, forma femenina de móros, a su vez implica destino y

7. Il. $24,747-760$.

8. ¡Ay, ay! ¿Qué le falta para lamentarse a esta desgraciada que ha perdido su patria, sus hijos y su esposo? (Tro. 105-7).

9. “¡Ay, ay! ¡A quién la paciente anciana servirá, en qué lugar de la tierra, como un zángano, este despojo, esta silueta de un cadáver, esta imagen inútil de los muertos! ¡Ay, ay! ¡Seré portera junto a la entrada o nodriza de niños yo que tuve el honor de gobernar Troya? (Tro. 190-5).

10. R. Scodel, "The captive's dilemma: sexual acquiescence in Euripides Hecuba and Trades", HSPh 98, 137-154, 137-138.

11. B. Russel, History of Western Philosophy, and its Connection with Political and Social Circumstances from de Earliest Times to the Present Day (London: Routledge, 1996), 13. 
muerte; se extiende sobre los sucesos enmarcados en el lapso de vida y la llegada a su fin. No supone desgracias, sino cumplimiento de la naturaleza mortal del hombre.

Las descripciones homéricas y hesiódicas de la Moira, a pesar de sus diferencias, coinciden en atribuirle la observancia de la justicia y la asignación ecuánime de las partes de cada uno; tal es su garantía, a la que todos los dioses están subordinados. Esta perspectiva permanece activa en la tragedia de Esquilo ${ }^{12}$. La Orestíada advierte que la justicia no depende de los hombres, sino que ellos deben adscribir a un orden moral de leyes superiores; si lo traicionan, adviene el mal trágico ${ }^{13}$.

Pero, es bien conocido que Homero advierte sobre las acciones con pretensión de libertad

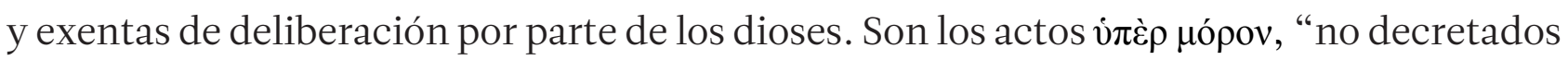
por el destino", es decir, obrados “por encima de lo dispuesto por la Moira” o "por encima de la determinación". En la épica, cuando adviene el destino como fatalidad y muerte, como cumplimiento de la Moira personal, los dioses se apartan sin importar cuánto quieran terciar a favor de sus predilectos; la forma de pensamiento que alberga el género acentúa la oposición divino-humana ${ }^{14}$. No obstante, una segunda dimensión de la Moira - más significativa para nuestro planteo- es la del hypermóron, lo provocado por encima de la determinación, espacio netamente humano, incapaz de detener lo fijado, aunque sí de agravarlo. Tal como la Moira no es de injerencia de los Olímpicos, tampoco lo es el hypermóron.

Se prolonga al espacio trágico una nota del mundo homérico: los dioses tutelan y acompañan las gestas humanas, pero cuando se retiran o se comportan como observadores pasivos, la vida se oscurece, cae en incertidumbre. ${ }^{15}$ Hay tragedia porque se siente esa desorientación y porque el héroe no se paraliza, sino que se arroja a su libertad; tal la posibilidad del hypermóron.

12. “(Moiras) deidades que a todos asignáis el destino con rectitud, que estáis vinculadas a cada casa, y en todo momento ejercéis el peso de vuestra misión y en todas partes sois las más honradas entre los dioses porque vuestro trato se ajusta a la justicia” (Aesch. Eum, 963-7).

13. J.-P. Vernant,P. Vidal Naquet, Mito y tragedia en la Grecia antigua, t. II, (Barcelon: Paidós, 2002 (1972)), 27-28.

14. W. Otto, Los dioses de Grecia. La imagen de lo divino a la luz del espiritu griego (Buenos Aires: EUDEBA, 1976), 219.

15. “¡Oh, Zeus! ¿Qué he de decir? ¿Acaso que tú miras a los hombres, o que, sin motivo, tienen en vano esa creencia [falsa, pensando que existe el linaje de las divinidades], y el azar se ocupa de todo lo de los hombres? (Hec. 488-91) 
El pensamiento filosófico que prepara las bases de la polis, también ubica la noción de Moira que asigna lo bueno y lo malo, sin atender a la previsión del hombre. Es decir, lo que deba suceder, sucederá; sin embargo, esta idea convive con la aceptación de la aptitud personal ${ }^{16}$. El concepto de determinación expresa que en la vida humana hay un ciclo definido, que no puede ser alterado ni por los mismos dioses, aunque, en esa porción, el hombre puede agregarse males causados por su propia necedad. Tal el sentido que expresa Zeus mismo en la Odisea ${ }^{17}$, que la acción libre puede producir la desmesura del agente y su doble pago de culpa, la inicial y determinada por la propia Moira y la añadida por libre intrepidez; pero la tragedia de Eurípides, sin negar la creencia inicial, añade un componente positivo: es posible la transformación del hacer personal para el bien, no para empeorar lo dado.

Referirse, así, al hypermóron de un personaje -de hecho, sólo los héroes se reservan estas decisiones- siempre indicará acciones que, partiendo de lo dado, intentan rectificarlo, completarlo por la imperfección de sus consecuencias. Esta clase de hypermóron es reclamada por la heroína en cuestión. Así como el héroe épico obra sabiéndose en conexión con lo divino -independientemente del fracaso o de la gloria que se le depare ${ }^{18}$ el personaje trágico de Eurípides enfrenta el destino con la fe debilitada y no puede entregar su confianza en los dioses ${ }^{19}$.

La Moira homérica es básicamente negativa en tanto marca el fin y la sucesiva decadencia ${ }^{20}$. La caída de Troya es el cumplimiento supremo de la Moira, lo cual permite conjeturar que todo lo que pase después de Troya es hypermóron y como tal sólo cuadra a los mortales promoverlo. Éste es el espacio en que la madre puede convertirse en destino.

\section{Condiciones de la acción materna}

En las dos obras seleccionadas para la reflexión, predomina una visión pesimista de la vida, expresada en el fin violento e innecesario de los hijos inocentes. A la muerte sin

16. W. Jaeger, Paideia: Los ideales de la Cultura Griega (México: F.C.E., 1962), 145.

17. “¡Oh dioses! De qué modo culpan los mortales a los númenes! Dicen que las cosas malas les vienen de nosotros, y son ellos quienes se atraen con sus locuras infortunios no decretados por el destino" (I, 32-4). 18. En las obras de matriz troyana se justifica doblemente, porque la caída de Troya, representada en el mejor de sus hijos, está marcada por la comprensión de Héctor de que los dioses lo han engañado y abandonado, tal como en Il., XXII, 209-13 y XXII, 296-303.

19. "En vano les hicimos sacrificios" (Tro. 1242).

20. W. Otto, Op. cit, 225. 
culpa hay que agregar el distanciamiento de la causalidad divina: los dioses parecen xpresar que han fracasado en la guerra y, por ende, se apartan dejando los despojos. El barrido completo de Troya se duplica al confirmarse tanto en la clausura de la estirpe de Príamo como en el abandono de la tutela divina.

El desplazamiento de los dioses de su responsabilidad ante el destino desvía el concepto de culpa. La objetividad de la maldición que pesa sobre el inocente y el modo de cargar con ella -trama de la peripecia dramática- es rechazada. En tanto crece la percepción de injusticia de los dioses, aumenta la idea de no culpabilidad del sujeto. Sin dioses presentes no hay medida de falta, en tanto ellos representan la justificación de los acontecimientos por extremos que sean. El orden cósmico desorientado imprime desorden al espacio moral. Así como en el ámbito de la épica el morir de los héroes es natural y, entonces justificado por la lógica cósmica ${ }^{21}$, en la tragedia se expone la barbarización de los fines en la muerte de los herederos, que no es conducente más que a ahondar odio, violencia y padecimiento ${ }^{22}$.

En ese contexto, determinado por la noción de Moira homérica - pero no limitado a ellase esboza el carácter femenino y materno. Sin tutela divina, las funciones tradicionales deben redefinirse, supliendo lo que se percibe insuficiente.

Las condiciones de la acción están planteadas: Troya ha caído, los dioses la han abandonado, sólo hay dolor para los justos y la aparente responsable, Helena, es la única que permanecerá impune. Toda reflexión se de-fundamenta: si no hay dioses en los cuales confiar, no queda posibilidad para una justificación religiosa de los hechos, entonces las decisiones y los espacios de acción caen en manos de fuerzas ciegas. El moderno Eurípides desplaza la firmeza de la Anánke -como destinación general-y de la Moira -en tanto parte de cada uno-bajo las móviles posibilidades de la Tyche. La confianza del hombre clásico expresada en el mito, la convicción de que vive dentro de un espacio daimónico de razón suficiente anterior a su comprensión, busca convertirse en certeza mediante el análisis de la razón; pero su resultado no será ya ni confianza ni certeza, sino que se desmembrará en difusas posibilidades de ser. La razón subjetiva inicia la desorientación del núcleo divino, sustituyendo destino por indeterminación; el nuevo orden la Tyche señala que puede

21. G. S. Meltzer, Euripides and the Poetics of Nostalgia (Cambridge: Cambridge Univeristy Press, 2006), 195. 22. ¡Oh, griegos, inventores de suplicios bárbaros! ¿Por qué matáis a este niño que de nada es culpable? (Tro. 764-5). 
pasar cualquier cosa y eso no consuela.

En definitiva, el hombre igualmente sufre, y saber el motivo, tener las razones justificadas no disminuye la carga. Mas, en orden de finalidad, saber el porqué del dolor permite darle sentido, ponerlo en cauce, dirigirlo hacia un modo de valoración de la propia existencia. La tragedia no busca disolver del dolor, sino darle "el” lugar que lo justifique.

\section{Hécuba y sus dos formas de Moira}

En ambas tragedias, Hécuba y Las Troyanas, se puede advertir un tratamiento diverso de la noción de Moira expresada en la persona de Hécuba. Partimos de la premisa de que la visión euripídea cuestiona la presencia divina después de la caída de Troya y de la suerte sufrida por sus defensores. Lo que sigue a la derrota, señal suprema de cumplimiento de la determinación, ya no importa porque no pertenece a los dioses y eso demuestran al alejarse. Después de la caída no hay espacio heroico propiamente dicho, pues los defensores han muerto, los sobrevivientes débiles son sacrificados, asesinados en represalia o repartidos como botín rápidamente. Sólo quedan en condiciones de resistir algunas mujeres. Y en esa relectura del mito troyano la épica heroica se hace tragedia femenina y específicamente materna.

Hécuba, la que fue madre de todos, se convierte en portavoz de la Moira, promesa de cumplimiento y cierre de los destinos aún pendientes. En el centro de las dos obras citadas, es relevante la pérdida de los descendientes más frágiles, Polidoro y Polixena en Hécuba y el pequeño Astianax en Las Troyanas. De los cincuenta hijos que el mito le atribuye a la esposa de Príamo, los que restan son plenamente indefensos ${ }^{23}$. La figura de la madre, que ofició como matriz inicial, se reconfigura como sede final, observando el paso de las generaciones y buscando condiciones de justicia para completar el movimiento del destino.

\subsection{Hécuba}

La pieza Hécuba muestra cómo la fuerza aquea se ensaña con los hijos menores, Polidoro y Polixena; pero, como si no fuera suficiente, a la fuerza de la guerra y sus normas, se suma la traición a la palabra dada, consecuencia de la desvalorización de los vencidos. El hijo menor y último vástago de los reyes caídos ha sido enviado con el rey Polimnéstor en busca de protección; él podría ser el retoño de la nueva Troya. Pero la ambición del falso aliado termina con el heredero, a quien asesina deshonrando los deberes de hospitalidad. 
Hécuba se entera del crimen al mismo tiempo en que se le ordena ofrendar a su hija como víctima sacrificial de Aquiles. En ese acto descubre el cadáver del hijo. Su furor no puede actuar solo y busca refuerzo para la represalia; se humilla ante Agamenón, el máximo enemigo, a su vez dueño de su exquisita Casandra, para suplicarle ayuda. Agamenón y Ulises serán testigos de la terrorífica vieja a la que creen haber dominado. Pero la intención de Hécuba no es contra Grecia ahora, sino contra el sinsentido posterior; el "después" de la guerra, de consecuencias invalorables por interminables ${ }^{24}$. Hécuba ejecuta su venganza como signo de hypermóron.

La doble violencia transforma a la madre despojada para convertirla en ejecutora de la compensación de sangre; en ese acto asume tanto los códigos del guerrero -valentía y violencia- como las fuerzas de la tierra. La Moira restituye sangre por sangre; Eurípides se retrotrae al orden pre-olímpico con coherencia, puesto que los nuevos dioses han desaparecido. A desprotección de los Olímpicos, se instaura un orden primitivo que no busca justicia sino sólo legitima el dolor, aumentándolo en los otros. La madre que ama a sus hijos y se conduele con sus males, mata salvajemente a los hijos del rey traidor en su presencia y luego lo ciega, eternizando esta última visión para hacerle permanente la experiencia fatal.

Consumada la voluntad de los dioses en la caída de Troya, Hécuba asumela razón divina bajo formato de impulso terrenal: ella misma, madre tierra, se convierte en proto-divinidad telúrica y ejerce sus poderes de fuerza ${ }^{25}$. La energía vital propia de la engendradora por excelencia muta en energía mortal, que religa por la sangre derramada de los otros. La idea de alteridad se extrema en una común barbarie; finalmente los civilizados y los justos, perdido su orden, se reducen a salvajismo.

Porque las formas de la vida, concluida forzosamente su virtualidad positiva, siguen su lógica de fuerzas: engendrar y destruir para engendrar es el curso del perpetuo movimiento de la naturaleza. La Moira inserta en ese movimiento poniendo fin a una fase, cortando el hilo, para permitir la sucesión de ciclos. La madre se entiende a sí misma en esa función.

24. "No sé a cuál de los males he de mirar, porque muchos hay presentes. Pues si toco uno, éste no me deja, y, a su vez, desde allí me reclama otra tristeza que suplanta unas desdichas con otras desdichas" (Hec. 585-90).

25. “...para el que ha hecho cosas vergonzosas el castigo es terrible. Un espíritu divino, que te es hostil, te ha pagado" (Hec. 1085-88). 
Hécuba no es aquíuna madre mítica tanto como una diosa dela tierra que agrega a los límites de duración propios de toda existencia una acción por encima de la determinación; si se suma a la muerte natural, fin predispuesto de la Moira, lo hace para reconocer la densidad de esa vida: Polimnéstor debe penar como traidor, en cumplimiento proporcional a una hybris donde reveló su carácter completo. Ella ayuda a cumplir el destino de Polimnéstor, que requería de una consciencia final, como corporización de una Moira personal que adviene a darle su medida. En el mismo acto de venganza, retribuye justicia sobre el hijo, la víctima inocente ${ }^{26}$. El carácter que muestra Hécuba en esta pieza se define por la pérdida del efecto civilizador que provee una religión arraigada en la estructura social: la madre está forzada a actuar radicalmente ante la señal de injusticia.

\subsection{Las Toyanas}

En las playas de Troya, una multitud abrumada espera el reparto de los vencedores. Los dioses acuerdan las suertes finales ${ }^{27}$; creer en la victoria es sólo un espejismo. Retirados Poseidón y Atenea, Hécuba da unidad al desgranarse de males: Polixena, Casandra, Andrómaca y la misma reina, desfila cada una con su destino adverso. El culmen del dolor es la caída del último varón de Troya en el niño Astianax. Entonces, no como satisfacción, pero al menos como percepción de una cierta razón cósmica, hay una apariencia de justicia en los límites del mito: la culpable Helena, será castigada por el esposo. Pero, esta apariencia se deshace muy pronto - la incitación sofista está actuando- y un escepticismo final domina los ánimos. La verdadera despedida de Troya, de la estirpe, de su potestad de reina, se cumple con el entierro del nieto en el escudo del hijo, el gran Héctor.

Entre los griegos era prerrogativa exclusiva de la familia tributar los ritos fúnebres para que el deudo no sufriera la condena de su alma ${ }^{28}$.

En la obra alternan las sucesivas quejas de las protagonistas que desfilan mostrando su irreversible sufrimiento ${ }^{29}$; pero los lamentos, acompañados constantemente por las reafirmaciones de las mujeres del Coro, se suspenden en el momento argumental en que

26. "Pues lo que se debe a la justicia y a los dioses no se desvanece de un solo golpe (...) Dejarás la vida bajo una mano que no hacía la guerra (Hec.1026-1031).

27. P. Vidal Naquet, L'honneur perdu et retrouve d'Euripide, transcripción de la conferencia dada en la Academiadel Sur (Buenos Aires, abril de 1997), 37.

28. W. Burkert, Religión griega arcaica y clásica (Madrid, 2007[1997]), 257-263.

29. A. Melero, Eurípides. Cuatro tragedias y un drama satírico (Madrid: Akal Clásica, 1990), 22. 
Helena y Hécuba disputan sobre la culpa de Troya, principio y sucesión de males.

Naturalmente la postura de ambas es diferente, pero converge en un punto dramático: en la causa de Troya los dioses se diluyen tras afanes humanos, es decir, la Moira se desvanece en su sentido de justicia, la parte de cada uno no es necesaria sino arbitraria. Y esa es la mayor injusticia, especialmente para quienes cargan todas las penas; porque mientras las vírgenes y las viudas troyanas son humilladas, la ramera griega volverá sana a su casa ${ }^{30}$.

La imposibilidad de que un acto de justicia aminore el sufrimiento genera la reacción materna al igual que en Hécuba. En Las Troyanas se yergue una nueva muerte, que viene a renovar la insensatez de la guerra: parece suficiente para cerrar la Moira que los héroes caigan. Pero el encadenamiento que se genera culmina en el asesinato del heredero, un pequeño estrellado desde los muros que debía proteger algún día.

La muerte del indefenso, sumada a la confirmación de que Helena, la culpable inicial no es -o no parece ser- culpable y entonces no tendrá castigo, representan la síntesis del destino; ambos momentos marcan el inicio y el fin de la guerra. Carece de importancia la conclusión sobre la culpa porque lo que degrada es la sospecha sofística: es suficiente poner en duda si fue o no Afrodita la que arrobó los ánimos de Paris y Helena, si fueron o no Hera y Atenea las que jugaron con Héctor y Aquiles. Lo irrebatible es que si no hay causa de la culpa, no hay finalidad para restaurarla. El antiguo orden cae.

La arcaica ley de la Erinnia vengadora no tiene objeto aquí como en Hécuba y parece insistimos en la sospecha racional- parece que la Moira en tanto cumplimiento tampoco tiene que ver con el orden divino. No obstante, el dolor extremo exaspera; la diferencia con la otra Hécuba es que en Las Troyanas, obra posterior cronológicamente y coexistente con una historia político-militar en riesgo ${ }^{31}$, el dolor no genera furor, sino piedad. La reina queda sola para dar sepultura a todos los suyos en el cuerpo destrozado de un bebé. La debilidad física y psicológica posterior al desastre, revela no obstante, en esta misión autoimpuesta y restauradora, una fortaleza anímica suprema ${ }^{32}$. En el hacer de la madre - que opera en el límite de la existencia de los que ha engendrado- hay una acción sacral expresada en el cumplimiento de las honras fúnebres.

30. "El amor de los dioses por Troya se ha ido" (Tro. 859).

31. E. Delebecque, Euripide et la guerre du Péloponnèse (Paris: C. Klincksieck, 1951), 245-262.

32. "Marchad, enterrad al cadáver en su desdichada tumba. Ya tiene todos los adornos que necesitan los muertos"(Tro. 1246-7). 
La piedad es el hypermóron renovado de Hécuba en Las Troyanas, la acción que se ubica por encima de la carga del destino y llega incluso a mejorarlo; ese acto final se reviste de una extraña pureza, de una virtualidad restauradora. En esa acción ritual une a su familia en el doble seno del escudo de Héctor y de la tierra. Hécuba siembra su semilla por segunda vez, fuera del tiempo y sus adversidades.

\section{Relación entre las obras: el carácter materno}

Si bien los dramas exteriorizan semejanzas, su sentido íntimo no lo es. Ambos inician con el escenario de Troya caída, la flota griega aprestándose para hacerse al mar y las mujeres en espera de sus próximos infortunios; ambas describen la cima de males, la muerte del rey y de los héroes, las ruinas del reino; ambas recrean la pérdida de dos hijas, la joven Polixena como ofrenda sacrificial para la tumba de Aquiles, Casandra sacrificada al lecho de Agamenón; ambas aparentan un dejo de esperanza en la salvación del varón joven, Polidoro, protegido en la corte del rey de Tracia a cambio de cuantiosos tesoros, Astianax el pequeño émulo de Héctor y ambas ubican su cambio de fortuna en la certeza de haber perdido tal esperanza; repetidamente las obras insisten en el supremo heroísmo de los vencidos y en la mezquindad de los vencedores. También y como fundamental, ambas obras centran los debates y decisiones en las fuerzas del hombre, los lamentos en boca de las desafortunadas mujeres y denuncian la reserva de los dioses, cuya presencia nominal opera sólo como telón de fondo que acentúa la soledad. Hay finalmente en ambas, una exhortación a la comunidad civil: la guerra deja la razón política desbaratada. Después la guerra, donde dos órdenes confrontan y uno queda eliminado, no hay progreso sino barbarización ${ }^{33}$.

Expuesta la crisis de la religiosidad olímpica, tal como Eurípides la presenta -duda de la presencia divina, cuestionamiento de su justicia- hay una modificación del nexo entre los hombres. Ante el dudoso vínculo con lo divino, la recuperación de la instancia religiosa se da en el formato de relaciones horizontales y es ejercida por la madre; a su vez, ésta no es cualquier madre sino la más sufriente, apta para el sacrificio.

La madre entonces se convierte en mediadora de destino, completando los últimos actos reivindicativos de su descendencia en una doble dirección. En particular, la reina

33. Vela, J., "Warfare, History and Literature in the Archaic and Classical Periods: the Development of Greek Military Treatises". Historia 53.2, 2004, pp. 129-146, p. 129. 
representa dos tipos de hypermóron ante los dioses inactivos. Hécuba, medida del dolor, muestra dos Moiras, dos modos de dar la parte a cada uno, modos destinados a responder cómo se soporta el sufrimiento y asociados en cada caso a un modelo de religiosidad, la Moira pre-olímpica y la Moira helenística.

Por un lado, en Hécuba, el carácter engendrador revierte en voluntad anti-vida: amar a los suyos se identifica con "vengar a los suyos" y culmina en "exterminar a los otros". La Moira no alcanza para ser el destino completo, se necesita el acento humano, decisión, riesgo, agravamiento, finalmente, intento de libertad. Esta madre ocupa y completa el espacio que la antigua creencia atribuía a fuerzas cósmicas, toma los destinos y contribuye a su cumplimiento ya personal, ya cívico; puesta ante los dioses y sin esperar más de ellos, el poder la madre se ejerce por encima de la determinación. No es divinidad, pero actúa como un daimon. La protagonista de Hécuba rehabilita la Moira pre-olímpica y como tal mira al pasado de la religiosidad, haciéndolo más representativo que al mundo olímpico.

Es la misma Moira la que engendra a las Erinnias y su derivación en Euménides. Pero la Hécuba de Las Troyanas desiste de actos de sangre que claman venganza y trata de restituir actos de desagravio que encomian la vida ejemplar. En el cuidado de las honras fúnebres y su función en la memoria, se establece un nexo de paz con los dioses y con las generaciones. Es el reclamo de Poseidón al principio de la obra. Hay allí un acto cultual que en su cumplimiento está haciéndose conmemoración: Hécuba sabe que otros cantarán los dolores de Troya. Así el enterramiento puede convertirse en fiesta, en su originario sentido religioso.

Con la elección de este segundo modo del hypermóron hay un avance hacia la noción de Tyche helenística. El apartamiento de los dioses no sólo se resuelve con disputas racionales en busca de las causas, sino también con gestos de piedad que tienen una misión religatoria, cuando menos de los hombres entre sí; si es preciso hacer silencio respecto de lo que los dioses quieren, no lo es respecto de lo que los hombres pueden establecer entre sí. La reformulación de la idea de destino tiene un componente humano muy poderoso; si la determinación de la antigua creencia acentúa la negación ${ }^{34}$-determinación es siempre conciencia de un límite- al "no" se antepone un "quizá", un "quizá esto que acontece irreversible pueda tomarse de otro modo". Este "tomar de otro modo" supone una nueva forma de entender, no mediada por la descomposición racionalista, como criticará el autor en sus falsificados discursos sofistas; 34. W. Otto, Op. cit., 225. 
no se trata de encontrar el argumento para que la subjetividad se tranquilice, sino de observar la evolución en el carácter de la madre que, porque comprendió lo incomprensible -hecho voluntad por los dioses- actuará finalmente de un modo no combativo, sino conciliador.

Este cambio no implica lógicamente alteración de la Moira como necesidad -no venceremos la mortalidad- pero cambia el obrar horizontal mientras tanto llega el fin. Aquí interviene la índole compasiva de la madre. La madre actúa allí donde la justicia divina o humana se ha retirado. Su acción puede no alcanzar como suprema restitución, pero es presencia activa donde nada ni nadie ha quedado en pie.

El helenismo difumina el horizonte con una problemática noción de azar -recordemos que azar es lo incierto y no controlable- pero antes, Eurípides sugiere una instancia regulable y decidida que tiene la capacidad de reconciliar en conductas éticas. La idea de compasión que está en Las Troyanas supera la noción de "parte por parte" de Hécuba, realza la noción de destino y abre la posibilidad de un modelo ético para el mundo que adviene.

La conducta de Erinnia que define a la madre en Hécuba torna en modo de Euménide en Las Troyanas; su maternidad evoluciona internamente - seguirá su dolor indeclinable- al quedar configurado un modelo de asentimiento. La mujer del mito se asimila a la divinidad de Démeter, paradigma de la pérdida siempre prematura de la descendencia. El carácter materno hará posible un modo de re-nacimiento, una transformación del pathos en vida.

\section{Reclamo de actualidad}

Eurípides es el poeta trágico que más asonancias muestra entre sus obras y los sucesos contemporáneos ${ }^{35}$. La misma relación podemos extrapolarla a otros momentos históricos. La pregunta a partir de la lectura de Hécuba y de Las Troyanas puede ser: ¿Cuál es el sentido del sufrimiento cuando el destino de los hombres es abandonado por los dioses? La pregunta actualizada podría ser: ¿En dónde hallamos un espacio de reconciliación ante el dolor del mundo cuando no hay confianza en un orden trascendente? Eurípides establece un ligamen, que es válido por encima de su contexto histórico ${ }^{36}$.

35. N.T Croally, Euripidean Polemic. The Trojan Women and the Function of Tragedy (Cambridge: Cambridge Classical Studies, 1994), 163-248.

36. G. Murray, Eurípides y su tiempo (México, D. F., 1949, [1913]), 84 ss. 
De la guerra sin fines para los dioses y, en consecuencia, insensata para los hombres queda un único rédito: sobreabundancia de muerte y dolor. En ese estado de parálisis sin perspectiva queda el mundo ${ }^{37}$. ¿Hay acaso acción que absuelva para recomenzar? Eurípides muestra un modelo de madre que no puede impedir el dolor, pero que puede restituirle sentido, primero superando el hypermóron de la mera venganza, luego usándolo como medio de consciencia social y finalmente honrando la memoria.

En la galería de perfiles maternos de Eurípides, la evolución de Hécuba como personaje pacificador ofrece un perfil único: la que todo lo tuvo, la más afortunada, la que fue madre, esposa y reina, y descendió al completo despojamiento de sus prerrogativas, se reconstituye desde el mismo abandono. De este modo, su hacer materno restaura la vida

que alguna vez dio y le fue quitada, en una analogía de renacimiento a partir del cuidado de los inocentes perdidos. Hécuba excede las funciones esperadas de su maternidad sin dejar de ser carácter femenino. A exigencias en el límite de lo humano, respuestas proporcionales. Si el destino impone el desafío, ella también desafía.

En la medida en que atendamos la interpelación del autor, podremos tener más elementos para pensar relaciones actuales entre espacios asolados por la injusticia y sociedades sumidas en la desorientación ulterior. Al menos compartimos con el griego tres rasgos: la sensación dominante de la ausencia de lo divino como razón causal, el decurso de un tiempo histórico que no se define sin violencia, las multitudinarias víctimas inocentes que corresponden al "daño colateral"; igualmente compartimos la pregunta por el sentido de todo ese caos. El carácter diferencial de la madre en medio de la fragilidad de las relaciones interpersonales se prefigura como una heroica obligación pendiente.

37. E. Delebecque, Op. cit., 14. 


\section{Referencias bibliográficas:}

W. Burkert, Religión griega arcaica y clásica (Madrid, 2007[1997]).

S. Campese, P. Manuli y G. Sissa, Madre materia. Sociología e biología della donna greca (Torino: Boringhieri Editori, 1983)

E. Cantarella, La calamidad ambigua. Condición e imagen de la mujer en la antigüedad griega y romana, (Madrid: Ediciones Clásicas, 1991[1985]).

D.J., Conacher, Euripidean Drama. Myth, Theme and Structure (Toronto: University of Toronto Press, 1967).

N.T Croally, Euripidean Polemic. The Trojan Women and the Function of Tragedy (Cambridge: Cambridge Classical Studies, 1994).- E. Delebecque, Euripide et la guerre du Péloponnèse (Paris: C. Klincksieck, 1951).

Eurípides, Tragedias, Introducción, traducción y notas de A. Medina González y J.A. López Pérez. Madrid: Gredos. 1983.

Euripides. Euripidis Fabulae, vol. 1. Gilbert Murray (Oxford: Clarendon Press, Oxford, 1902).

Euripides. Euripidis Fabulae, vol. 2. Gilbert Murray. (Oxford: Clarendon Press, Oxford, 1913).

G.M.A Grube, The Drama of Euripides (Londres: Methuen, 1941).

W. Jaeger, Paideia: Los ideales de la Cultura Griega (México: F.C.E., 1962).

J.C. Kamerbeek, “Mythe et Réalité dans l'OEuvre d'Euripide”, Entretiens sur l’Antiquité Classique (Ginebra: Fondation Hardt VI, 1960).

N. Loraux, Las experiencias de Tiresias. Lo masculino y lo femenino en el mundo griego 
(Barcelona: Editorial Acantilado, 2004[1990]).

A. Melero, Eurípides. Cuatro tragedias y un drama satírico (Madrid: Akal Clásica, 1990). G.S. Meltzer, Euripides and the Poetics of Nostalgia (Cambridge: Cambridge University Press, 2006).

G. Murray, Eurípides y su tiempo (México, D. F., 1949, [1913]).

W. Otto, Los dioses de Grecia. La imagen de lo divino a la luz del espíritu griego (Buenos Aires, EUDEBA, 1976).

Luigi Pati, "La famiglia, sistema relazionale fragile e vulnerabile, ma ricco di risorse". En La Famiglia, Rivista di problemi familiar (Brescia: Editrice La Scuola, 2015).

B. Russel, History of Western Philosophy, and its Connection with Political and Social Circumstances from de Earliest Times to the Present Day (London: Routledge, 1996).

R. Scodel, "The captive's dilemma: sexual acquiescence in Euripides Hecuba and Trades", HSPh 98, 137-154.

J. Vela, "Warfare, History and Literature in the Archaic and Classical Periods: the Development of Greek Military Treatises". Historia 53.2, 2004, 129-146.

J.P. Vernant, P. Vidal Naquet, Mito y tragedia en la Grecia antigua, t. II (Barcelona: Paidós, $2002(1972))$..

P. Vidal Naquet, L'honneur perdu et retrouve d'Euripide, transcripción de la conferencia dada en la Academia del Sur (Buenos Aires, abril de 1997). 